\title{
Negotiating a 'Scary Gap’: Doctoral Candidates, 'Writing Up’ Qualitative Data and the Contemporary Supervisory Relationship
}

\author{
Robin Humphrey ${ }^{1} \&$ Bob Simpson ${ }^{2}$ \\ ${ }^{1}$ Faculty of Humanities and Social Sciences, Newcastle University, Newcastle upon Tyne, UK \\ ${ }^{2}$ Department of Anthropology, Durham University, Durham, UK \\ Correspondence: Robin Humphrey, Faculty of Humanities and Social Sciences, Newcastle University, \\ Newcastle upon Tyne NE1 7RU, UK. Tel: 44-191-222-6763. E-mail: robin.humphrey@ncl.ac.uk
}

Received: October 29, 2012 Accepted: November 13, 2012 Available online: December 3, 2012

doi:10.11114/jets.v1i1.10

URL: http://dx.doi.org/10.11114/jets.v1i1.10

\begin{abstract}
The complex task of 'writing up' qualitative data provides difficulties and challenges for both doctoral candidates and their supervisors, which can often result in detrimental effects on the supervisory relationship. These effects can be heightened by the pressures currently felt by supervisors, not least to ensure their supervisees submit in a timely fashion. We argue here that these pressures are in part responsible for a shift in supervisory pedagogy from a relational to a processual grounding. This article addresses some of the consequences of these effects via analysis of interviews with doctoral candidates and their supervisors from a series of interdisciplinary research training workshops in the UK designed to provide help for doctoral candidates engaged in writing up qualitative data. In these workshops doctoral candidates came together briefly for a residential workshop along with peers at the same stage of the doctoral cycle who were away from their institutional homes. We discuss the relationship between process and relationality and how a workshop of this kind might impact on writing and help with timely submission.
\end{abstract}

Keywords: doctoral education, writing groups, qualitative research methods, doctoralsupervision, interdisciplinary study programme

\section{Introduction}

Among academics, the supervisory relationship with a doctoral candidate is considered a very special one. A complex amalgam of scholarly guidance, moral support and friendship, the supervisory relationship is key to the reproduction and development of disciplinary expertise and application. During the last twenty years or so, this relationship has been in flux as the doctorate itself has been transformed by a range of fundamental developments (Taylor, 2009, McCallin \& Nayar, 2012). Our interests here are in supervisory relationships in the social sciences, and specifically in those where the research is based on qualitative methodologies, where we argue there are particular, but widespread, difficulties and challenges faced by both doctoral candidates and their supervisors at the post-fieldwork stage when the 'data' has to be 'written up' into a thesis of doctoral standard (Humphrey and Simpson, in press).

Many doctoral candidates find the complex task of writing up their qualitative fieldwork data difficult and possibly traumatic, especially if they find themselves feeling 'stuck' (an image which featured commonly in doctoral candidates' feedback accounts of what they were experiencing) and in a state of liminality (Kiley, 2009). Finding oneself in such a state can both have detrimental effects on the supervisory relationship (leading to e.g. a sense of abandonment, feelings of blame, or lack of confidence in the relationship) and be damaging to the candidate (crises of confidence, lack of belief in their own abilities, disenchantment with their project, etc.), and progress on the thesis can be impeded.

An awareness that many doctoral candidates across a wide range of disciplines were experiencing difficulties in writing up their qualitative data provided the impetus for the Writing Across Boundaries (WAB) project, based in the North East of England. We were also acutely aware of the pressures on doctoral supervisors, not least to ensure that their doctoral candidates submitted their theses on time. In this article, we focus on the related problems associated with writing up qualitative data and progressing the thesis for timely submission. 
As part of the WAB initiative we collected extensive feedback to help with evaluation and development of the workshops. However, we became increasingly aware that important lessons could be learnt about the contemporary doctoral process from further analysis of this data. Specifically, we look at how our workshops have helped doctoral candidates to make progress in their writing by removing them temporarily from the complex pressures of the supervisory relationship and allowing them to explore their writing and analytic strategies freely with others at the same stage of their doctorates. First, we briefly outline the changing nature of the doctorate and the impact these changes have had on the supervisory relationship.

\section{The Changing Nature of the Supervisory Relationship}

The doctoral supervisory relationship was first established early in the 19th century when Wilhelm von Humboldt proposed that the $\mathrm{PhD}$ should be awarded for making an original contribution to knowledge and understanding of science, rather than be a means for accrediting teaching as it had been hitherto (Taylor, 2009). Humboldt's proposal was first introduced in Berlin in the early 19th century, and since then has been reproduced across the globe, albeit in different ways.

The supervisory relationship in the Humboldtian doctorate was one in which the 'precocious few were called to emulate the master as scholar' (McWilliam \& James, 2002: 7). Supervision was conducted in private spaces remote from conventional academic teaching (Taylor, 2009), and the underlying rationale was that 'if one can do research then one presumably can supervise it' (Rudd, 1985).

In the UK and many other countries across the world, however, doctoral education has been transformed, and the impact on supervisory practice has been profound. Taylor (2009) outlines the developments in the doctorate, and discusses the implications for supervisory practice in the post-Humboldtian doctorate. He identifies eight major developments, mainly stemming from changes in public policy, the globalistation of education and the desire to produce highly skilled doctoral graduates for the so-called 'knowledge economy' (see also Usher, 2002).

The implications for supervisory practice discussed by Taylor (2009) include a move away from the 'master-apprentice' paradigm, a marked increase in doctoral candidate numbers, and a requirement to support doctoral candidates to submit and complete on time within an institution's regulatory framework that includes monitoring progression, maintaining throughput, quality assurance and quality enhancement (McWilliam, 2004). What these changes amount to is a fundamental shift in emphasis from a relational grounding of doctoral pedagogy to a processual one.

Whereas supervision was once more or less a private province involving an individual academic and his or her doctoral candidate, with little in the way of guidance for new supervisors and limited external accountability for their actions and outcomes (Johnson, Lee \& Green, 2000), now doctoral supervision is often likely to be carried out by a team of supervisors, who have access to supervisory training, and the process is typically scrutinised by a range of quality assurance procedures (Manathanga, 2005).

In the UK, these changes have been underpinned by A Code of Practice for Research Degrees, published nationally by the Quality Assurance Agency for Higher Education (2004). This Code introduced minimum standards for research degree programmes, including team supervision and annual monitoring of progress, and alignment with the Code has been audited by the QAA within its regular institutional visits since 2006-7. Transferable skills training is now an integral part of the British doctoral experience, with a well established national body, Vitae, coordinating the development of skills training funded by Research Councils UK, the coordinating body of the UK Research Councils.

\section{Doctoral Submission and Completion Rates}

Much of the impetus for the structural changes which began to move emphasis onto the processual aspects of supervision came from low doctoral submission and completion rates, a subject of concern in the UK, and particularly to funding bodies (Humphrey, Marshall \& Leonardo, 2012). These concerns were also echoed in Western Europe (Kehm, 2004, Maher, Ford \& Thompson, 2004) Australia (Bourke, Holbrook, Lovat, \& Farley, 2004; Sinclair, 2004; Kiley, 2011), Canada (Elgar \& Klein, 2004) and the United States (Golde, 2005; Council for Graduate Schools 2008, 2009, 2010). Along with the arts and humanities, the social sciences were seen to have particularly low submission rates (Wright \& Cochrane, 2000), and as a consequence the UK Economic and Social Research Council (ESRC) has been in the vanguard when introducing remedial changes to the management of the doctoral studentships that they fund. From the 1990s the ESRC has required both generic and discipline-specific research training requirements, to be fulfilled before universities are granted the recognition needed to apply for ESRC studentships. Strict submission rates were also introduced. If $60 \%$ of ESRC-funded candidates did not submit their theses in four years the host institution would be sanctioned and thereafter unable 
to apply for ESRC studentships for up to two years (ESRC, 2010).

Such changes have been controversial. Deuchar (2008), for example, contends that the style of research supervision academics adopt has been adversely affected. He argues that these changes have taken place in a context where higher education in the UK is increasingly dominated by a market-driven, consumerist ethic underpinned by a neo-liberal focus on efficiency and economies of scale and the predominant image is one of doctoral candidates as rights-bearing customers. Supervision, as Deuchar goes on to argue, has been shaped by the quantifiable expectations imposed by external bodies responsible for funding and overseeing doctoral research provision. In addition to submission rate monitoring, performance in doctoral activity in the UK is a key indicator in the Research Assessment Exercise (now Research Excellence Framework), where the source and volume of research studentships gained and the number of doctoral degrees awarded is a fundamental, albeit crude, way of assessing the quality of an institution's research environment. Completion rates as a proxy for strength and vitality of the research environment has fed into an increased pressure on academics to ensure that their candidates finish on time (Grant, 2005), and has, we argue, led to a focus on the processual aspects of doctoral supervision.

\section{The Writing Across Boundaries Project}

Within this pressured environment, what help can be offered to supervisors to assist them to perform their role successfully and efficiently, and to research candidates to help them get the best from an evolving framework of supervisory expectations? These questions helped to frame a project designed to help social science doctoral candidates write up qualitative data. The Writing Across Boundaries (WAB) project stemmed from the realisation that post-fieldwork writing was a particular cause of anxiety to doctoral candidates and their supervisors alike, and that little help was on offer at this critical phase, when fieldwork has been completed and analysis and writing begins in earnest.

The genesis for the project and the details of the annual workshops are described more fully elsewhere (Simpson \& Humphrey, 2008, 2010). The popularity of the workshops was testimony to the widespread problem that we had identified, but the effusive feedback from the participants and their supervisors came as a surprise and, we felt, warranted further attention. The analysis of this extensive feedback data generated a number of key themes which, when linked to the growing literature on doctoral pedagogy, helped us understand what had transpired in the workshops.

Our analysis showed that the WAB workshops provided an opportunity for post-fieldwork doctoral candidates to reflect on the writing process, and in turn on themselves as academic researchers. As we were to discover, this proved crucial when it came to helping candidates gain confidence in their intellectual expression in writing and to (so we would argue) helping the workshop participants to move more confidently into the final stage of their doctoral theses, increasing the chances of them submitting on time and enhancing their development into autonomous, academic researchers.

The focus of this article is a more detailed analysis of what it was about the workshops that produced these effects. In particular, we consider the ways in which writing, the supervisory relationship and the processes and expectations which now characterise doctoral training are being configured in practice. Our analysis highlights factors which may make it difficult for doctoral candidates (and indeed their supervisors) to manage a shift in emphasis from a relational to a processual framing of doctoral training, often resulting in a delay in progressing the thesis. In conclusion, we offer suggestions as to where efforts might be expended to assist doctoral candidates to make a conceptual leap across an important and difficult threshold in their developing competence and insight and furthermore get the best from supervisory relationships, their peer group and their institution.

\section{The Content of the Workshops and Methodological Strategy}

The Writing Across Boundaries workshops were the centrepiece of a project funded by the UK's Economic and Social Research Council as part of its Researcher Development Initiative. ${ }^{i}$ They comprised five participative sessions, delivered by anthropologists, sociologists, a psychologist (who was also a creative writer) and an educationist: an introduction by the organisers, which included a panel of past WAB participants who reflected on their strategies for writing up qualitative data in their theses; ordering text; analysing the relationship between text and representation; rhetoric and narrative in qualitative writing; and data and theory.

The first two workshops were regional, and open to applicants from the five universities in the North East of England. The third workshop was opened up to applicants from any university in the UK, and the fourth and fifth workshops were advertised throughout Europe, with application details available via our website. ${ }^{\text {ii }}$ The most important criteria used for selection were that the doctoral candidate should be at a post-fieldwork stage and 
writing a thesis based in part or entirely on qualitative data. Out of a total of 286 applicants for the four workshops 201 participants were drawn from 39 UK universities and, in the last two workshops, from universities in the Netherlands, Poland, Portugal, Switzerland, Belgium, the Irish Republic and the Czech Republic.

The workshop participants were drawn from a very wide range of social science disciplines, and included some who were trained and located in the natural sciences, the medical sciences and the humanities. Participants were using a wide range of qualitative methodologies, most commonly interviews (70\%) and participant-observation (42\%). Most researchers (71\%) were employing a combination of qualitative methods, and some (12\%) were combining qualitative analysis with that of quantitative data.

A three-stage strategy was adopted for the formal evaluation of the first three workshops funded through the ESRC award, although the data we use here stems from the third stage, where semi-structured telephone interviews were conducted six months after the workshop with participants but also, separately, with their supervisors to assess whether any longer-term impacts had arisen from the workshop. The response rates for stage three were $53 \%$ for candidates and $50 \%$ for their supervisors. All the data were processed and stored electronically on the software package Nvivo in preparation for analysis, and the themes that emerged were traced across the three cohorts of participants and their supervisors.

We have discussed elsewhere two of the major themes to emerge from our analysis, the importance of the affective domain in the writing process and the identification of writing up qualitative data as a threshold concept in doctoral research (Humphrey and Simpson, in press). The last theme highlighted what we saw as an important point in academic pedagogy and one which is critical for doctoral candidates in their emergence as autonomous, professional researchers. In this article we take this argument further by concentrating on two further, related themes that emerged from our analysis of the data: first, the role of peer learning communities in helping some doctoral candidates to cross this important threshold in their professional researcher development; and second, why this crossing can be difficult to negotiate within the supervisory relationship.

\section{Learning Communities and Peers in Doctoral Writing}

A central feature of the WAB workshop was the creation of a learning community made up of doctoral candidates from a range of disciplines all of whom were at similar stages in the research process. The formation of this community of peers was arguably as important as the timetabled sessions given by academics over the two-day workshop. There were 185 references to this factor in the feedback data, and most of these related to the confidence gained from being with fellow doctoral researchers all of whom were actively engaged with writing up their qualitative data. For example:

Probably the most valuable of all was the temporal community of $\mathrm{PhD}$ candidates. We all undertake PhDs in different subjects, but experience the same issues. Knowing others go through the same issues and also hearing of how others tackle these issues give a lot of confidence to go ahead and just do it, rather than thinking and wondering if what we are doing is right. (anonymous feedback, workshop 2)

The realisation that the challenges and difficulties integral to this stage of the research process were shared was evidently beneficial, as vividly expressed by a Sociology doctoral candidate: 'It was kind of a group therapy. That moment on thefirst day when [the organisers] asked "Who finds writing difficult?", that was a real light-bulb moment for me.' Although we did not set out to do 'therapy', the sharing of the emotions evoked by analysing and writing up qualitative data helped many participants re-evaluate them in terms of objective issues of pedagogy and practice, rather than simply as private pains:

I really liked meeting people that are going through the same difficulties. You feel confident seeing others suffer, not that I'm wanting them to suffer. I mean, you feel that's its not that you are stupid - it's that a $\mathrm{PhD}$ is harder than writing just $1 \& 2 \& 3$. In that sense it was very beneficial for my confidence. (doctoral candidate in Urban Planning, workshop 1)

The honesty of this group of peers about the difficulties inherent in the writing process was also commonly mentioned in the feedback, which posed the question of why this level of honesty is worthy of repeated praise:

Yeah, what I found most useful was the honesty about the writing up process. Here you've got a group of people acknowledging just how messy writing is, you draft and re-draft. I mean you know that intellectually but I felt more confident about it. I mean I have this horrible vision, a sense of shame about the file they [supervisors] must have on all my work. Sometimes I think I'd just prefer them to burn it. But it really helped to stand back and understand the process. (doctoral 
candidate in Sociology, workshop 3)

One answer to the question of why frankness and openness are so valued is the fact that the participants did not know each other prior to the workshop, and were therefore unconstrained by the dynamics that often exist within groups of $\mathrm{PhD}$ candidates when working within their home institutions. There can be competitive behaviour among a student peer group, which can result in an unwillingness to admit that things are difficult:

They [other PhD candidates] say 'just do it'. It gave me confidence to be in a group of people I didn't know, I felt I have nothing to prove to them. Like if you don't know something you're not intellectually disabled or anything like that. Everyone had similar problems, and they are not problems of your own conceptual clarity, they are problems everyone has. I actually started to write a first draft afterwards and it all came very instantly. (doctoral candidate in History, workshop 3)

Such comments provide substantive evidence for what has been described as the socially situated nature of academic writing (Aitchison \& Lee, 2006; Wellington, 2010). Indeed, recognition that a doctoral candidate's writing can benefit from shared activities has given rise to a small, but growing literature on the pedagogical potential of learning about writing in doctoral writing groups (Lee \& Boud, 2003; Aithchison \& Lee, 2006, 2010; Maher et al., 2008; Kamler \& Thomson, 2006; Aitchison, 2009a,b).

The Writing Across Boundaries workshops share some of the key characteristics of writing groups reported in the literature, in particular the concept of peer learning and the idea that social and emotional support for writing can be shared. However, they differ from these writing groups in three important respects. First, the learning community was established over an intensive two-day residential period and disbanded afterwards, rather than developing through successive meetings over time. Second, the workshop participants were not defined by a single discipline (Maher et al., 2008); here, the common element was a series of methodological problematics arising from the relationship between analysing qualitative data and writing. Third, the participants came from a large number of universities in the UK and further afield. Kamler and Thompson (2006) identify scholarly writing as a major site of anxiety for doctoral candidates and their supervisors, and seek to remedy this situation with a call for universities to address more seriously the question of doctoral research writing and to establish 'institutional writing cultures' (p. 144). Without wishing to undermine this noble call, we can say that an element in the success of the WAB workshops was the doctoral candidates breaking out of both their disciplinary and institutional homes and spending focused time with their peers from other disciplines and institutions.

\section{Negotiating a New Supervisory Relationship}

The newly acquired confidence that workshop participants described also brought with it some important challenges for the supervisory relationship which we had not anticipated. Taking responsibility for the analysis and writing up of qualitative data requires a candidate to exert control over their thesis to a degree that marks this process out as an important threshold. Moreover, as researchers get over this threshold dependence on supervisors necessarily reduces and researcher autonomy increases, yet this often takes place at a point where expectations of supervisory input may be heightened. From initial reliance on supervisors for guidance on how to shape and carry out a piece of doctoral research, the doctoral candidate should ideally take increasing control over their project and, by the time of submission and then examination, have a more or less complete sense of control over and ownership of their thesis.

Supervisors have primary responsibility for facilitating this development, although this can be impeded by difficult interpersonal dynamics, mistrust, mutual lack of confidence and so forth (Manathunga, 2002; Lovitts, 2008), and poor supervisory relationships have been associated with doctoral candidates taking longer to complete their theses (Bair \& Haworth, 2004; Golde, 2000; Ives \& Rowley, 2005; Wright, 2003). These relational difficulties experienced in the supervisory relationship can also be heightened by the processual pressures put on supervisors to ensure that the thesis is submitted and completed on time.

At the beginning of the research we were mindful of the possible tensions between our attempts to evaluate the workshop and the sensitivities that could arise in relation to supervisory relationships. We made it clear to workshop participants from the outset that our purpose was not to undermine, critique or threaten their relationships with their supervisors. Similarly, at the start of telephone interviews with supervisors we informed them explicitly that we were not exploring the supervisory relationship per se and that the focus was on candidates' writing. Even so, ample evidence came from doctoral candidates and supervisors about the change in the supervisory relationship brought about by reported increases in confidence and in analytic ability on the part of the supervisee to write up their data, possibly in part as a result of the supervisee overcoming the reluctance many doctoral candidates feel to discuss their inability to complete research tasks with their supervisors for fear 
of 'not looking professional' (Ahern \& Manathunga, 2004: 243).

For the workshop participants these changes invariably resulted in more productive working relationships:

My supervisor wanted me to go to the workshop because [he thought] I was slow about writing. I think my supervisor worried that if I wasn’t writing I wasn’t progressing with my $\mathrm{PhD}$. He thought [the workshop] was really good for my confidence. He has really changed his approach, he's endorsing everything now. I think that's really good feedback for supervisors. Being a mentor is a lot about giving you confidence rather than questioning everything that you do. He's quite excited about it now, and I'm not scared about writing. I sit down in front of my word processor with a blank screen and feel inspired, or I sit down and draw a mind-map. It took me a long time to work that out. (doctoral candidate in Design, workshop 3)

Increased knowledge of the research process and confidence in decision making can also lead to the research work progressing in the way that supervisors intended but might have found difficult to bring about:

The main thing I discussed [with my supervisor] was about how to separate what goes in the thesis and what goes to the funder, and my supervisor said 'Isn't that what I've been telling you all along!' But talking to the people at the workshop, it's one thing to know it, it's another to actually hear about it being done, to actually feel that it's alright, that it's not being dishonest and not hiding your findings. (doctoral candidate in Health Care, workshop 3)

Most supervisors welcomed the confidence boost that their supervisees experienced through the workshop as representing progress in their development as researchers:

There was certainly an increase in confidence, and a maturing as a result of the workshop. Her research method became more conscious, and she is now more tolerant of the contradictions inherent in the process. There is more reflexivity in her intellectual journey: she is now more aware of how the interactive element in her interviews, for example, has contributed to the nature of the data she has collected. (supervisor of doctoral candidate in Education, workshop 3)

According to the following two supervisors, the positive impact on their supervisees has been profound, with dramatic changes in their research skills taking place:

I noticed that [the supervisee] did seem more confident in her project, exuding much more enthusiasm and optimism. It's as if the scales had fallen from her eyes, and she saw the way forward through a half-full glass rather than a half-empty one as before. Also her writing became clearer, as she relied more on narrative than tortured correlations. I did think that the workshop was a defining event for [the supervisee], and I hoped that it would prove to be a lasting watershed or epiphany, laying the foundations for a more settled period of research as she came to the serious business of writing up her thesis. (supervisor of doctoral candidate in Politics and Marine Science, workshop 3)

Before the workshop, I had a "student in crisis". My student, a professional clinician, has been able to reconcile the tension between doing therapeutic work for her clients, whilst at the same time regarding that work as an object of research. She now sees herself as "living these research results" and is producing in her thesis a narrative account of her relationship with herself and her clients. (supervisor of doctoral candidate in Physiotherapy, Workshop 3)

The final comment from a supervisor presented here does not concern the supervisee specifically, but is more a reflection on the supervisor's experience of several doctoral candidates all of whom have had problems at the same stage of their research, and on the difficulty supervisors have in helping their supervisees overcome such problems:

From experience with other students it does seem to me that this particular aspect of $\mathrm{PhDs}$ is where many students can come unstuck as it were, especially if they are working in an interdisciplinary field [and using qualitative methods] which means they may be a novice when it comes to this kind of work. What's more this experience of feeling like a novice can generate a great deal of anxiety at a point in the PhD cycle - typically second half of year 2 FT onwards when they can't afford to lose confidence or momentum if they are going to submit on time. I am not sure exactly why they don't seek help [from their supervisors] on this but speculate that it might be because it happens at a time when they think they are supposed to know what they are doing so they don't want to admit they are having problems. In other words there may be a mismatch between their perceived expectations of competency in research terms and then how 
they feel at this stage of their work. Any extra support at this stage is valuable. Sometimes the students really need to see other students working through the same problems - it is very powerful to be able to identify with peers when you are having problems. (supervisor of doctoral candidate in Cultural and Heritage Studies, workshop 2)

In short, some doctoral candidates had found the workshops helpful in enabling them to deal with feelings of being 'stuck' and increasingly frustrated as writing up post fieldwork failed to progress in the way that they expected and also the way that they thought others were expecting it to. The workshop helped them negotiate an important 'threshold' from a position of increased confidence. Supervisors, for their part, also appeared to have felt frustration, as their strategies for helping candidates at this stage were not as productive as they had hoped for with unproductive tensions arising as a result. Their feedback suggested that the workshop had provided their candidates with a confidence that they were more able to work productively with yet had struggled to instil by themselves.

\section{Conclusion}

The conclusion we reach from the analysis of our feedback data is that providing doctoral candidates with an opportunity for a brief but intensive immersion in a community of peers at the same stage of the doctoral cycle is highly beneficial. Cast in the idiom of a rite of passage, the workshop captured a moment (post-data collection/fieldwork, and as writing begins in earnest) which is characterised by anxiety but also pregnant with possibility (Turner 1986). For many participants it offered the opportunity to reflect upon what is often an ongoing struggle for control over the messiness of qualitative data and the creative impulses necessary to render it into clear and analytically mature and original text of doctoral standard. In ways that we hadn't fully appreciated at the outset, the workshop as ritual thus offered an experiential approach to the 'scary gap' of writing up qualitative data and converting it, as one participant aptly put it, into a 'creative playground'.

Not only did the workshop facilitate writing abilities, but in many cases it had a significant impact on the supervisory relationship. In our follow-up interviews with candidates and supervisors we were able to gain some insights into the dynamics which had led to these changes: free expression in a non-judgmental setting with a temporary learning community of peers away from their disciplinary, institutional and supervisory homes.

As we outlined in the introduction, the WAB intervention comes at time of much wider structural change in the form and dynamics of doctoral supervision. A relationship which focused almost exclusively on sole supervision has developed into one hedged with codes of practice implemented by supervisory teams and supplemented by research training and support outwith the supervisory team.

In conclusion, we would suggest that this intervention, which ostensibly has the simple objective of supporting late-stage doctoral writing up of qualitative research, touches upon some deeper and more consequential issues of doctoral pedagogy. The elevation of process over relationality in doctoral supervision brings to the fore an ethos of standardisation and formalisation which problematises the uniqueness of the supervisory relationship. Paradoxically, because the workshops address the personal dimensions of writing, some candidates found a register in which to manage their creativity, competence and control which, we would suggest, also helped supervisors find a bridge between process and relationality, which might otherwise have become problematic.

We would not claim universal success in this regard, but the feedback we received from candidates and supervisors alike would suggest that the WAB workshop formula created the kind of stimulus that enabled the majority of participants to feel more confident in expressing themselves in their writing as independent academic researchers in their own right. Crucially, this in turn enabled supervisors to support their supervisees more effectively and to help them in their quest to progress their theses and increase their chances of submitting and completing in a timely fashion.

\section{Acknowledgements}

The authors would like to thank all the participants in the WAB workshops, both for their participation and for the time they gave us in providing the feedback which gave us both the data and the inspiration for this article. We would also like to thank their supervisors, who initially nominated them for a place on the workshops and then allowed us to interview them over the phone six months later. We are indebted to Carolyn McAlhone and Clare Hardy, from the Graduate School at Durham University, for magnificent administrative help with the workshops over the years. We thank, and acknowledge the work of, the doctoral students who helped with the workshops and data processing, Victoria Wood, Mwenza Blell, Alison Jobe, Sally Atkinson and Rachel Douglas Jones, and acknowledge with thanks the help with NVivo given by Dr Jane Wilcockson, and the insightful advice given by Dr Stan Taylor, Director of the Centre for Academic and Researcher Development, Durham Univevrity 
and by Dr Margaret Kiley of the Australian National University, regarding an early draft of this article. The Writing across Boundaries workshops are now conducted annually as Advanced Research Training in the ESRC-funded North East Doctoral Training Centre.

\section{References}

Aitchison, C. (2009a). Writing groups for doctoral education. Studies in Higher Education, 34(8), 905-916. http://dx.doi.org/10.1080/03075070902785580

Aitchison, C. (2009b). Research writing groups. In Writing Qualitative Research in Practice, ed. J. Higgs, D. Horsfall \& S. Grace. Amsterdam: Sense Publishers.

Aitchison, C. \& Lee, A. (2006). Research writing: problems and pedagogies. Teaching in Higher Education, 11(3), 265-78. http://dx.doi.org/10.1080/13562510600680574

Aitchison, C., \& Lee, A. (2010). Writing in, writing out: Doctoral writing as peer work. In Doctoral student's companion: Getting to grips with research in education and the social sciences, ed. P. Thomson \& M. Walker, London: Routledge.

Ahern, K., \& Manathunga, C. (2004). Clutch-Starting stalled research students. Innovative Higher Education, 28(4), 237-54. http://dx.doi.org/10.1023/B:IHIE.0000018908.3613.a5

Bair, C. R., \& Haworth, J. G. (2004). Doctoral student attrition and persistence: A Meta-Synthesis of research. In J.C. Smart (ed.) Higher Education Handbook of Theory and Research X1X. Dordrecht, Kluwer Academic, 481-533.

Bourke, S., Holbrook, A., Lovat, T., \& Farley, P. (2004). Attrition, completion and completion times of PhD candidates. Paper presented at the AARE Annual Conference, Melbourne, 28 November to 2 December 2004. Available online at http://www.aare.edu.au/04pap/bou04849.pdf, last accessed 21 August 2011.

Cornforth, S., \& Claiborne, L. B. (2008). Supervision in educational contexts: raising the stakes in a global world. Teaching in Higher Education, 13(6), 691-701. http://dx.doi.org/10.1080/13562510802452418

Council of Graduate Schools. (2008). Ph.D. Completion and attrition: Analysis of baseline program data from the Ph.D. completion project. Washington, DC: Council of Graduate Schools.

Council of Graduate Schools. (2009). Ph.D. Completion and attrition: Findings from exit surveys of Ph.D. completers. Washington, DC: Council of Graduate Schools.

Council of Graduate Schools. (2010). Ph.D. Completion and attrition: Policies and practices to promote student success. Washington, DC: Council of Graduate Schools.

Deuchar, R. (2008). Facilitator, director or critical friend? Contradiction and congruence in doctoral supervision styles, Teaching in Higher Education, 13(4), 489-500. http://dx.doi.org/10.1080/13562510802193905

Economic \& Social Research Council (ESRC). (2010).The importance of PhD submission rates, Available online at: http://www.esrcsocietytoday.ac.uk/ESRCInfoCentre/opportunities/postgraduate/training/recognition/submissio ns.aspx, last accessed 22 December 2011.

Elgar, R. J., \& Klein, R. M. (2004). What you don't know: Graduate Deans’ knowledge of doctoral completion rates. Higher Education Policy, 17(3), 325-36. http://dx.doi.org/10.1057/palgrave.hep.8300059

Golde, C. (2000). 'Should I Stay or Should I go?’ Student descriptions of the doctoral attrition process. The Review of Higher Education, 23(2), 199-227.

Available online at: http://muse.jhu.edu/journals/review_of_higher_education/v023/23.2golde.html

Golde, C. (2005). The role of the department and discipline in doctoral student attrition: Lessons from Four Departments. Journal of Higher Education, 76(6), 669-700.

Available online at: http://muse.jhu.edu/journals/journal_of_higher_education/v076/76.6golde.html

Grant, B. M. (2005). Fighting for space in supervision: Fantasies, fairytales, fictions and fallacies, International Journal of Qualitative Studies in Education, 18(3), 337-354. http://dx.doi.org/ 10.1080/09518390500082483

Humphrey, R., Marshall, N., \& Leonardo, L. (2012). The impact of research training and Codes of Practice on submission of doctoral degrees: An exploratory cohort study, Higher Education Quarterly, 66(1), 47-64. http://dx.doi.org/ 10.1111/j.1468-2273.2011.00499.x

Humphrey, R., \& Simpson, B. (forthcoming). Writes of passage: writing up qualitative data as a threshold concept in doctoral research, Teaching in Higher Education. http://dx.doi.org/10.1080/13562517.2012.678328 
Ives, G., \& Rowley, G. (2005). Supervisor selection or allocation and continuity of supervision: PhD students' progress and outcomes. Studies in Higher Education, 30(5), 535-55. http://dx.doi.org/10.1080/03075070500249161

Johnson, L., Lee, A., \& Green, B. (2000). The PhD and the autonomous self: Gender, rationality and postgraduate pedagogy, Studies in Higher Education, 25(2), 135-147. http://dx.doi.org/10.1080/713696141

Kamler, B., \& Thomson, P. (2006). Helping Doctoral Students Write: Pedagogies for supervision. London: Routledge.

Kehm, B. M. (2004). Developing doctoral studies and qualifications in Europe: Good practice and issues of concern - A comparative analysis, In J. Sadak (ed.) Doctoral Studies and Qualifications in Europe and the US: Status and Prospects. UNESCO, Bucharest.

Kiley, M. (2009). Indentifying threshold concepts and proposing strategies to support doctoral candidates, Innovations in Education and Teaching International, 46(3), 293-304. http://dx.doi.org/10.1080/14703290903069001

Kiley, M. (2011). Government policy and research higher degree education. Journal of Higher Education Policy and Management, 33(6), 629-640. http://dx.doi.org/ 10.1080/1360080X.2011.621189

Lee, A., \& Boud, D. (2003). Writing groups, change and academic identity: research development as local practice. Studies in Higher Education, 28(2), 187-200. http://dx.doi.org/ 10.1080/0307507032000058109

Lovitts, J. E. (2008). The transition to independent research: Who makes it, who doesn't, and why, The Journal of Higher Education , 79(3), 296-325. http://dx.doi.org/10.1353/jhe.0.0006

McCallin, A., \& Nayar, S. (2012). Postgraduate research supervision: a critical review of current practice. Teaching in Higher Education, 17(1), 63-74. http://dx.doi.org/10.1080/13562517.2011.590979

McWilliam, E. (2004). 'On being accountable: Risk-consciousness and the doctoral supervisor.' Paper submitted for full refereeing for the Australian Association for Research in Education Conference, Melbourne 28November-2 December 2004. Available online from: http://www.aare.edu.au/04pap/mcw04267.pdf, last accessed 15 November 2012.

McWilliam, E., \& James, R. (2002). Doctoral education in a knowledge economy. Higher Education Research and Development, 21(2), 117. http://dx.doi.org/10.1080/07294360220144033

Maher, M., Ford, E., \& Thompson, C. (2004). Degree progress of women doctoral students: Factors that constrain, facilitate, and differentiate. The Review of Higher Education, 27(3), 385-408. http://dx.doi.org/10.1353/rhe.2004.0003

Maher, D., Seaton, L., McMullen, C., Fitzgerald, Otsuji, E., \& Lee, A. (2008). 'Becoming and being writers': the experiences of doctoral students in writing groups, Studies in Continuing Education, 30(3), 263-275. http://dx.doi.org/ 10.1080/01580370802439870

Manathunga, C. (2002). Early warning signs in postgraduate research education: a different approach to ensuring timely completions. Teaching in Higher Education, 10(2), 219-33. http://dx.doi.org/10.1080/1356251042000337963

Manathunga, C. (2005). The development of research supervision: 'turning the light on a private space'. International Journal for Academic Development, 10(1), 17-30. http://dx.doi.org/10.1080/13601440500099977

Quality Assurance Agency for Higher Education (QAA). (2004) Code of Practice forthe assurance of academic quality and standards in higher education, Section 1 postgraduate research programmes.

Available online from: http://www.qaa.ac.uk/academicinfrastructure/codeOfPractice/section1/postgrad2004.pdf, last accessed 22 December 2010

Rudd, E. (1985). A new look at postgraduate failure. London: Society for Research into Higher Education and National Foundation for Educational Research. London: Nelson.

Simpson, B., \& Humphrey, R. (2008). Writing across Boundaries: Explorations in research, writing and rhetoric in qualitative research, Qualiti, 8, 10-12. Available online from: http://www.cardiff.ac.uk/socsi/qualiti/QualitativeResearcher/QR_Issue8_Jun08.pdf, last accessed 15 November 2012. 
Simpson, B., \& Humphrey, R. (2010) Writing across Boundaries: Reflections on the Place of Writing in Doctoral Research Training for Social Scientists. Learning and Teaching: The International Journal of Higher Education in the Social Sciences, 3(1), 69-91. http://dx.doi.org/10.3167/latiss.2010.030105

Sinclair, M. (2004). The pedagogy of 'good' PhD supervision: A national cross-disciplinary investigation of $\mathrm{PhD}$ supervision. Canberra: Department of Education and Training.

Taylor, S. (2009). The Post-Humboldtian Doctorate. in V. King, F. Deepwell, L. Clouder and C. Broughan (eds.) Academic Futures: Inquiries into Higher Education \& Pedagogy. Cambridge: Cambridge Scholars Publishing.

Turner, V. W. (1986). Dewey, Dilthey and drama: An essay in the anthropology of experience. In The anthropology of experience, ed. V. Turner \& E. Bruner. Urbana \& Chicago, IL: University of Illinois Press.

Usher, R. (2002). A diversity of doctorates: fitness for the knowledge economy? Higher Education Research and Development, 21(2), 143-53. http://dx.doi.org/10.1080/07294360220144060

Wellington, J. (2010). More than a matter of cognition: an exploration of affective writing problems of post-graduate students and their possible solutions', Teaching in Higher Education, 15(2), 135-150. http://dx.doi.org/10.1080/13562511003619961

Wright, T. (2003). Postgraduate research students - people in context? British Journal of Guidance and Counselling, 31(2), 209-227. http://dx.doi.org/10.1080/0306988031000102379

Wright, T., \& Cochrane, R. (2000). Factors influencing successful submission of PhD theses.Studies in Higher Education, 25(2), 182-195. http://dx.doi.org/10.1080/713696139

\footnotetext{
i The Writing Across Boundaries project was funded by the ESRC Research Development Initiative, grant number RES 035 25 0013. Further details of the RDI can be found at: http://www.rdi.ac.uk/

ii The project website can be found at https://www.dur.ac.uk/writingacrossboundaries/. Since its inception in June 2008, according to Google Analytics the 211 pages have been viewed 94,534 times, and its home page has recorded 19,836 Unique Pageviews, of which 12,773 have originated from outside the UK.
}

\section{(cc) $\mathrm{BY}$}

This work is licensed under a Creative Commons Attribution 3.0 License. 